LIVER REFERENCE

The Liver in Systemic Disease, edited by VK Rustgi and DH Van Thiel (1993). Raven Press, 1185 Avenue of the Americas, New York, NY 10036. 397 pages; US\$85.

This is a small (350 pages), easy to read, very useful reference book for the internist or pure gastroenterologist who has a patient in whom liver dysfunction seems to be part of a more systemic problem.

Some chapters have a particularly well written analysis of pathogenetic mechanisms - among the best were those written on cardiac disease, alcohol-induced liver damage, parasitic disease and coagulation disorders. The chapters on metabolic diseases and the liver, and the endocrine system were, by comparison, disappointing.

For once the chapter on hemochromatosis offered an explanation for other causes of high iron saturation or ferritin values aside from hemochromatosis although sadly the authors did not discuss the role of viral hepatitis in this saga, perhaps because the chapter was written by hematologists not hepatologists!

It was disappointing to see out-of-date references used in the early part of the chapter on inflammatory bowel disease really anything written before the advent of endoscopic retrograde cholangiopancreatography should be questioned, as the author later points out. This chapter was resurrected by an excellent review of primary sclerosing cholangitis although I would argue about the value of sequential cholangiograms to detect a superimposed cholangiocarcinoma.

The liver and pregnancy chapter was well written but left out any discussion on the management of adenomas, hemangiomas and focal nodular hyperplasia during pregnancy. The chapters on the hepatobiliary manifestations of acquired immunodeficiency syndrome gave a well balanced approach to this now-common clinical situation although I am convinced that hepatosteatonecrosis may indeed be found in the absence of any alcohol abuse in this situation.

The chapter on the liver and transplantation combined a practical approach to the differential diagnosis of liver dysfunction in the patient with an organ trans- plant with a superb description of the liver pathology so essential to confirm the clinical suspicion. Other chapters that were particularly helpful in the area of clinical management included again the chapter on alcohol and the liver (this really is an excellent chapter) and the chapter on Wilson's disease. Liver and ageing were discussed in great depth and, as with most chapters, this section was well referenced.

This book is a welcome addition despite the rapidly increasing number of books on liver disease, as it covers several topics that have been poorly covered in many standard texts. I recommend it to any internist or gastroenterologist.

Jenny Heathcote MBBS MD FRCP FRCPC Associate Professor, Department of Medicine University of Toronto Toronto, Ontario

\section{LARGE INTESTINE TEXTBOOK} The Large Intestine: Physiology, Pathophysiology, and Disease, edited by Sydney F Phillips, John H Pemberton and Roy G Shorter (1991). Raven Press, 1185 Avenue of the Americas, New York, NY 10036.

This text on the large intestine is worthwhile for anyone interested in having an up-to-date reference on all aspects of large intestinal function and disease. Doctors Phillips, Pemberton and Shorter from the Mayo Clinic have brought together a 'who's who' of investigators to deal with large intestinal function, which leads to the strength of the text and its broad coverage of all aspects of large intestinal function. The only negative comment one could make is that inflammatory bowel disease is only covered in three chapters, leading to a fairly superficial discussion of these disorders. However, since whole textbooks are available regarding inflammatory bowel disease, this book is recommended for those interested in other aspects of large intestinal function and dysfunction. It is a well written, up-to-date text. It can be recommended to anyone interested in a comprehensive reference on large intestinal physiology and pathophysiology.

Geoffrey K Tumbull MD FRCPC Associate Professor of Medicine Dalhousie University Halifax, Nova Scotia 


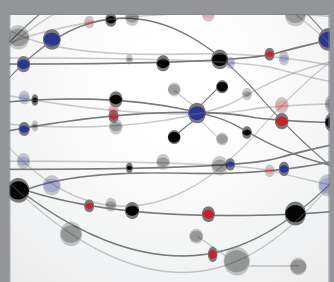

The Scientific World Journal
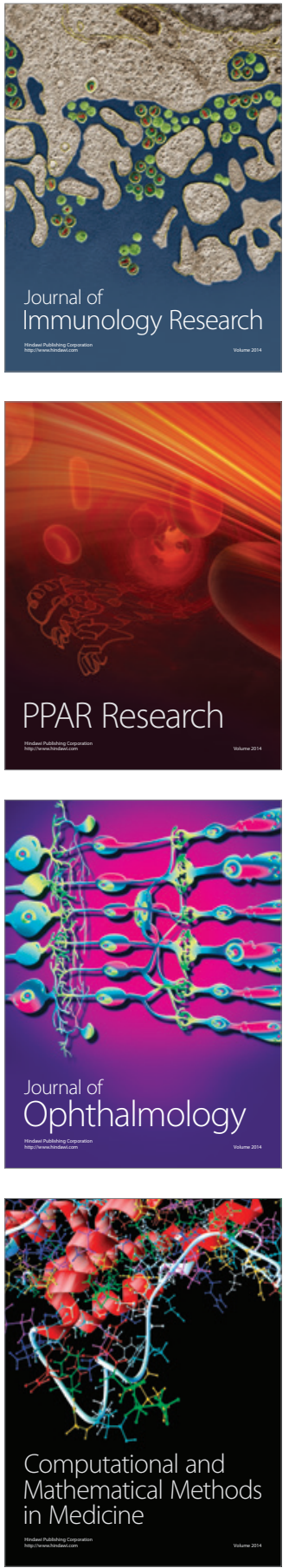

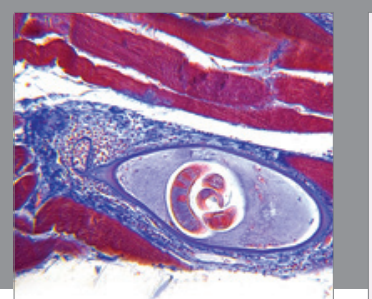

Gastroenterology Research and Practice

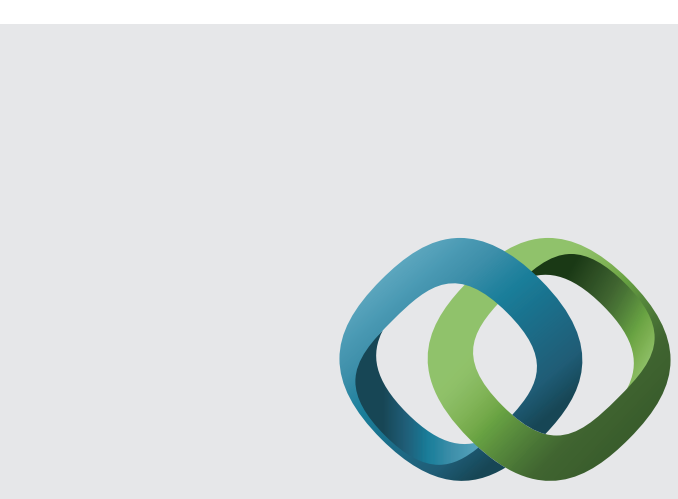

\section{Hindawi}

Submit your manuscripts at

http://www.hindawi.com
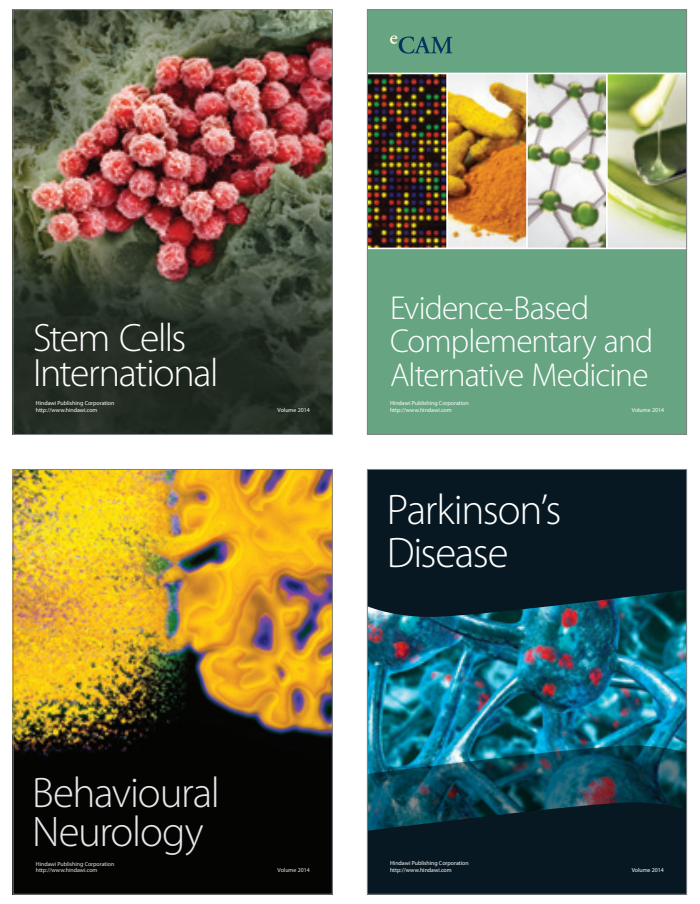
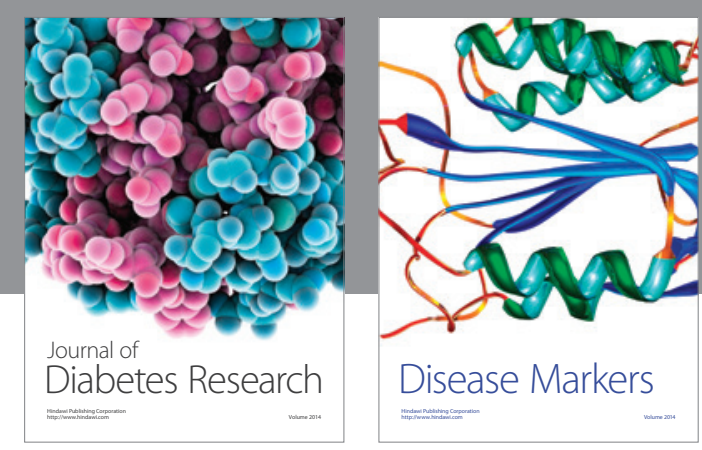

Disease Markers
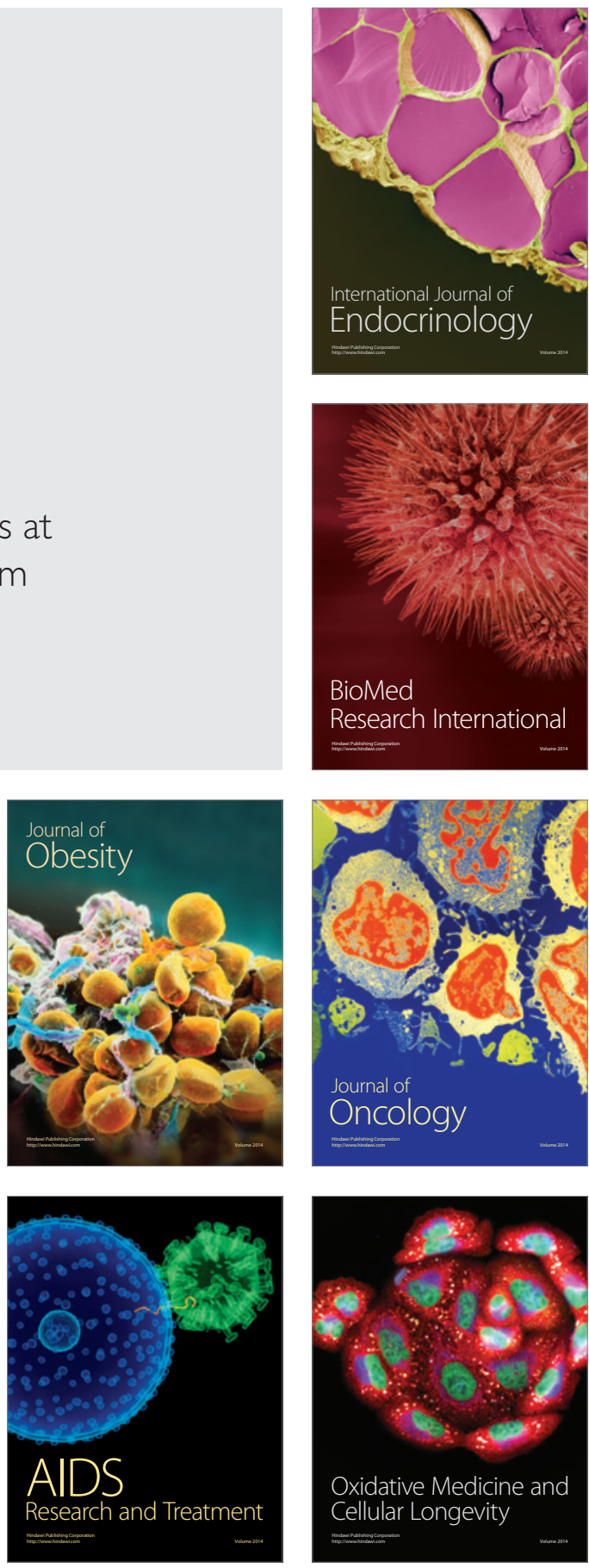